\title{
Numerical modelling of non-transform discontinuity geometry: Implications for ridge structure, volcano-tectonic fabric development and hydrothermal activity at segment ends
}

\author{
Stephen Tyler ${ }^{\mathrm{a}, *}$, Jonathan M. Bull ${ }^{\mathrm{a}}$, Lindsay M. Parson ${ }^{\mathrm{a}}$, George W. Tuckwell ${ }^{\mathrm{b}}$ \\ ${ }^{a}$ National Oceanography Centre Southampton, University of Southampton, European Way, Southampton, SO14 3ZH, UK \\ ${ }^{\mathrm{b}}$ STATS, Porterswood House, Porterswood, St Albans, Herts, AL3 6PQ, UK
}

Received 14 January 2006; received in revised form 19 February 2007; accepted 19 February 2007

Available online 24 February 2007

Editor: R.D. van der Hilst

\begin{abstract}
Ocean ridge discontinuities partition and offset spreading centres at a range of scales. Large scale discontinuities (10's-100's $\mathrm{km}$ ) are synonymous with first-order transform faults, which have well defined linear fault zone valleys. In contrast, NonTransform Discontinuities (NTDs) are diffuse, smaller scale offsets ( 0 to $<20 \mathrm{~km}$ ), characterised by central basins or topographic highs. The geometry of NTD offsets can be categorised by the sense of offset, either right-stepping or left-stepping, and by the relative positions of the segment tips. The segment tip configurations include under-lapping, over-lapping or simple across-axis jumps or stepping in the ridge axis. In this study finite difference software is used to model segment geometry at a slow-spreading ridge under a normal tensile-stress within a homogeneous and isotropic medium. Along- and across-axis segment separations were varied incrementally for left- and right-stepping senses. The results show that the ratio of along-axis to across-axis segment tip separation is a dominant control of stress field rotation within an NTD. Features which most clearly show rotation within an NTD include basins and tectonically controlled constructional ridges. The obliquity of these features along with measurements of the surrounding fault fabrics are used as a way of observing and determining stress rotations within NTDs along the Central Indian Ridge (CIR). These rotations were used to obtain segment geometries from models where the central tensor showed an equivalent rotation. The results show that geometry has a profound effect on stress field rotation under which large- and small-scale volcanotectonic fabrics form. In addition, a shortfall of the predicted model tip relative to interpreted positions, along with morphology and observation of the ridge fabrics at the terminations to some segments, suggests the existence of a zone, broadly analogous to the process zone observed in fracture mechanics, which we call a damage zone. Given the criteria for the promotion of hydrothermal circulation, this damage zone would have a greater potential for hosting hydrothermal activity.
\end{abstract}

(C) 2007 Elsevier B.V. All rights reserved.

Keywords: Central Indian Ridge; numerical modelling; Non-Transform Discontinuities; volcano-tectonic fabric; hydrothermal activity

\footnotetext{
* Corresponding author. CDSP, National Oceanography Centre, European Way, SO14 3ZH, UK. Tel.: +44 892451490.

E-mail address: st1@noc.soton.ac.uk (S. Tyler).
}

\section{Introduction}

Ocean ridge discontinuities partition and offset spreading centres into spatially and temporally independent segments at a range of scales, which are observed to 
migrate, lengthen or shorten over time [1,2]. Large scale and structurally organised discontinuities are synonymous with first-order transform faults which can offset a ridge by 10 's -100 's $\mathrm{km}$. Small or zero offset NonTransform Discontinuities (NTDs) have a more diffuse structure. They are important structures along oceanic ridges as they occur with a greater frequency than larger and more temporally stable transform offsets. Secondorder discontinuities correspond to small disruptions to the continuity of a ridge ( 3 to $<20 \mathrm{~km}$ ).

Although NTDs have small offsets, their influence on the lithosphere can be very important to the structure of an ocean ridge, most notably in the rotation of tectonic fabrics, rotation and control on volcanic construction and off-axis traces, through rifted basins and chevron structures or "wakes". Estimates from magnetic studies [1] suggest that $20 \%$ of the seafloor may be affected by the wakes of migrating discontinuities. This disturbance of the lithosphere may be a result of discontinuities occurring away from regions of partial melt and where the magma supply is reduced. The crust will be thinner and more geochemically fractionated and the balance between magma supply and extensional tectonism will induce increased stretching near discontinuities.

NTDs may initiate by sustained differential, asymmetric spreading occurring between two spatially independent segments $[1,2]$. Ultimately discontinuities, with the exception of transforms have a common origin linked to upwelling and segregation of mantle melt beneath the mid-ocean ridge which leads to propagation of magmatic pulses along the ridge [1]. The morphotectonic variability displayed by non-transform offsets however, suggests that discontinuities are influenced by a variety of factors including stress fields and lithospheric rheology [3]. NTDs respond to plate motion, local and far-field stresses in a different way to more structurally and temporally organised transforms. They also respond to processes associated with the way individual segments and groups of segments rearrange themselves in response to mantle diapirism, melt driven processes, changes in spreading direction, gravitational spreading and crack propagation [4]. NTD offset geometry has already been established as an important factor in crustal thickness and lithospheric structures associated with hydrothermal circulation [3-5].

Significant variation in NTD geometry and structure has been observed including en echelon jogs linked by parallel basins, en echelon jogs with over-lapping tips and oblique shear zones with extensional basins that trend approximately $45^{\circ}$ to the ridge axis $[1,3,4,6,7]$. Grindlay and Fox [3] used finite element analysis to examine the horizontal tectonic stress field produced by offsets at ridges with different spreading rates. The models suggested that non-transform offsets particularly along slow spreading ridges are zones of mechanical weakness relative to the lithosphere surrounding them. NTDs at slow-spreading ridges show a weaker resistance to shear relative to the ridge-normal stresses resisting plate motion. They proposed that an offset length of between 10 and $20 \mathrm{~km}$ is a stable length range for maintaining a transform fault geometry. A weaker ridge-normal stress relative to the shear stresses within a discontinuity produced models most closely resembling over-lapping spreading centre geometries observed along fast-spreading ridges. This distinct change in behaviour of lithospheric rheology and NTD geometry between fast- and slow-spreading ridges was attributed to magma-supply rates, relatively continuous at fast-spreading ridges and intermittent at slowspreading ridges. This study examines small $(<11 \mathrm{~km}$ across axis) offset NTDs at a slow spreading ridge. In contrast to the work of Grindlay and Fox [3] we consider stress distributions associated with variable along- and across-axis offset NTD geometries. We also use data and observation in conjunction with the numerical modelling to understand and directly apply model results to specific NTD structures along the CIR.

There are important implications resulting from the stresses surrounding discontinuities and the rotations generated in the tectonic and volcanic fabrics. Complex and cross-cutting fault populations coupled with a suitable heat supply, extracted by conduction and by advection in hydrothermal fluids circulating along faults and cracks [8], could promote hydrothermal circulation. Observations of cross-cutting fault fabrics have been made at the TAG hydrothermal vent site $[9,10]$ which exemplify the role of increased permeability through faulting and fissuring for the formation of hydrothermal systems away from segment centres. The required heat source may be generated from the serpentinisation of exposed ultramafic massifs in these regions, or through alongaxis transport of heat from magmatic centres $[5,11,12]$.

Theories on the geological setting for hydrothermal vent activity have required revision over recent years due to new observations and discoveries of vent sites along the world's ocean ridges. Only in the last $20 \mathrm{yr}$ has it been found that vent sites are not restricted to fastspreading ridges and that along slow-spreading ridges they are not restricted to the relatively warmer segment centres [5,13-15]. The thermal flux along ridge segments is reasoned to be at a maximum at segment centres, however it has been discovered that it can equally be focussed towards discontinuities where intersecting structural lineaments can act to enhance hydrothermal circulation [16]. Further evidence of 
hydrothermal circulation independent of segment centres has been found where vent signatures in the water column have been observed along fracture zones [17].

We document in this paper that NTD geometry has a profound influence on how tectonic and volcanic fabrics develop within a discontinuity. In order to understand how a favourable tectonic and volcanic setting may develop at NTDs for hydrothermal circulation, the geometrical influence on NTD stresses and volcanotectonic structure need to be understood. A geometrical classification of NTDs based on observation and structural criteria has already been attempted $[4,18]$. Three distinct types of NTDs were identified along the MidAtlantic Ridge. These included septal offsets, marked by a topographic ridge separating the spreading segments, a brittle/ductile extensional shear zone marked by oblique extensional fractures, and those NTDs with no accommodating structure and a $<5 \mathrm{~km}$ offset.

In general, NTDs can exhibit distinct geometries categorised by the sense of offset, right-stepping or leftstepping and by the relative positions of the segment tips (Fig. 1). The segment tip configurations include underlapping, over-lapping or simple across-axis jumps or stepping in the ridge axis. Significant oblique orientation of the large- and small-scale fabric within an NTD is strongly influenced by the sense and separation ratio of the offset.

This study will focus on detailed numerical modelling of a range of geometries and configurations for slowspreading ridge segments forming small-offset NTDs. The effects of these geometries on the stress fields within which the intra-NTD volcano-tectonic fabrics form will be examined and the dominant controls on the stresses, NTD morphology and volcano-tectonic fabric development will be described. Survey data collected along the Central Indian Ridge (CIR) provides data coverage across numerous NTDs and is an opportunity to directly analyse the model results with the observed CIR intraNTD volcano-tectonic fabrics using Geographical Information System (GIS) spatial analysis tools. The implications of these geometrical effects on hydrothermal circulation will also be considered.

The development of numerical models and observation of the model results in a spatial framework will address three fundamental questions (i) How does NTD geometry affect the interaction of stress fields generated by the segment tips in the interior of an NTD? (ii) How can these geometrical models help to define more clearly the mechanical limits of a segment (iii) What are the implications for locating potential sites for hydrothermal circulation based on the potential for enhanced crustal permeability at segment ends? In this paper we present generic numerical models for all possible NTD geometries, before specific application to three case studies along the Central Indian Ridge.

\section{Generic models}

Numerical modelling provides an appropriate solution for studying the effects of the large range of variables associated with the interaction of stresses in the oceanic lithosphere [19-21] and a large range of NTD geometries.

Fig. 1a summarises a generic Non-Transform Discontinuity geometry and the range of modelling that was completed. The spreading segments are shown separated by an along-axis distance $(Y)$ and an across-axis distance $(X)$, a particular NTD geometry can be expressed as a separation or separation ratio $(Y / X)$. The value of the Separation Ratio gives a complete description of the NTD: a value of +1.5 describing an NTD where the along-axis separation is 1.5 times the across axis separation (Fig. 1b - laterally offset); a value of 0 representing no along-axis separation (Fig. 1c stepping); a value of -1.5 representing segment overlap of 1.5 times the across-axis separation (Fig. $1 \mathrm{~d}$ - overlapping). The orientation of the stress tensor $(\theta)$ mid-way between the two segment tips is here termed the central stress tensor. In these initial models the orientation of $\theta$ changes anti-clockwise with increasing segment overlap.

In our models we use Fast Lagrangian Analysis of Continua (FLAC) [22] code to model cracks within a homogenous and isotropic medium. A single crack simulation using FLAC was compared to the theoretical stress field distribution for a single mode I crack in a homogeneous medium [23]. The results show a very good correlation both in the distribution and magnitude of the mean stresses around the crack.

In our models, the cracks (or segments) open in extension under a tensile far-field stress applied to the left and right boundaries of the grid. Lachenbruch [24] estimated the range of ridge strength to be of the order 10-30 MPa based on the upwelling of material within a conduit. We use a strength of $30 \mathrm{MPa}$ as a boundary condition for our numerical models. The elastic parameters used include a shear modulus of $2.9 \mathrm{MPa}$ [25] and a Poisons Ratio of 0.46 [25]. Our models assume a brittle crust present at the ridge axis however the depth or $Z$ axis is negligible relative to the $X$ and $Y$ dimensions of the model grid. We apply stresses integrated over time, which are represented as calculation steps within the model. The stress tensor distribution after an equilibrium condition is reached within the numerical models is used to compare the present day strains observed as tectonic fabrics along the CIR. 


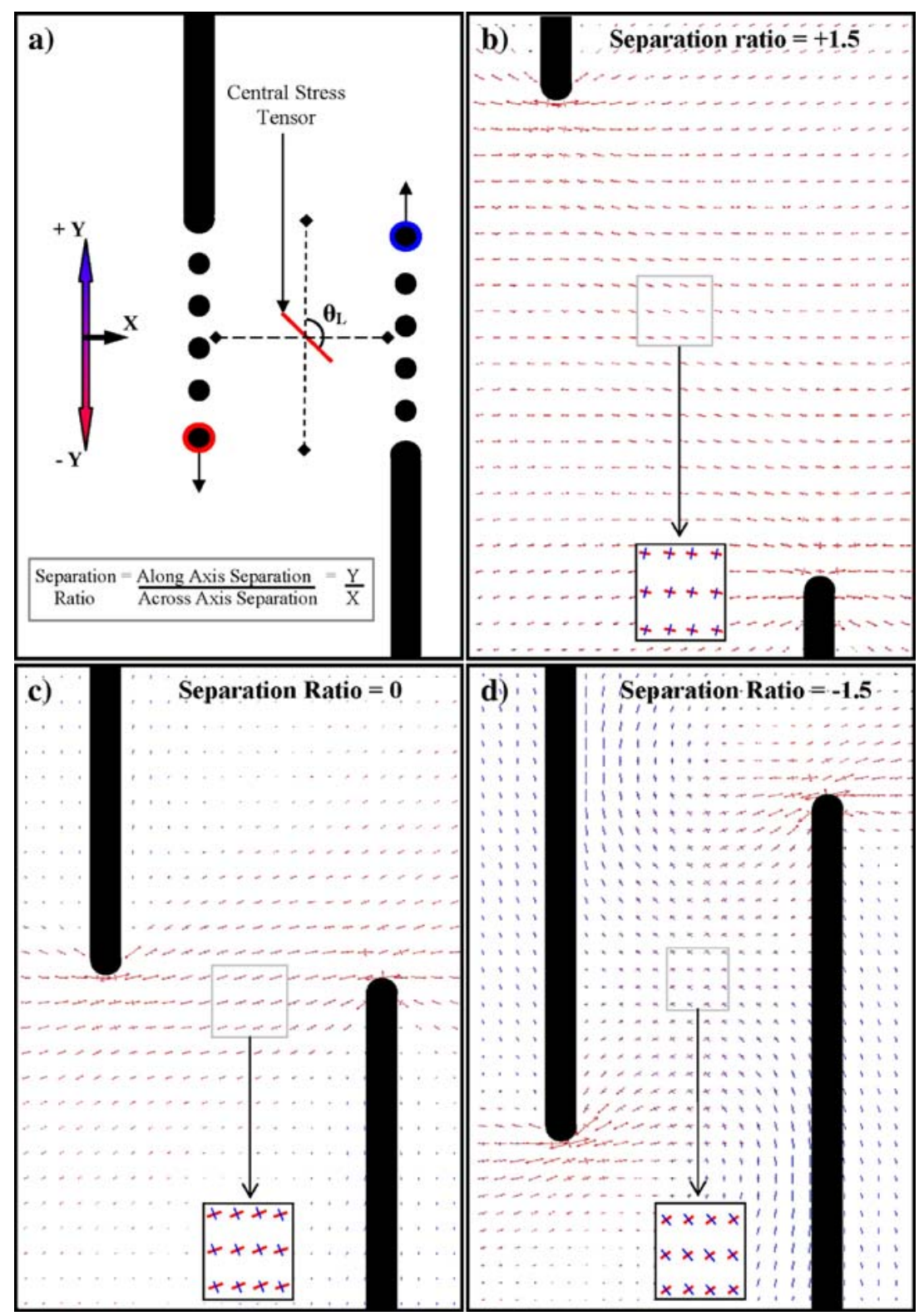

Fig. 1. A summary of the three fundamental NTD geometries. (a) The measurement criteria for the tensor rotation angle $\theta_{\mathrm{L}}$ and aspect ratio, for a leftstepping sense of offset. A right-stepping sense has the tensor rotation angle $\theta_{\mathrm{R}}$. The geometry of the NTD is defined using an aspect ratio of the along- and across-axis separations $(Y / X)$. (b) An underlapping geometry showing interaction of the segment tip stress fields and resulting rotation of the field between the crack tips. $\theta_{\mathrm{L}}=110^{\circ}$. The NTD stress field is represented by the stress tensors in red. The principal stresses $\left(\sigma_{1}\right)$, at each grid point are shown in blue and are at $90^{\circ}$ to the stress tensors (c) An across-axis stepping geometry, $\theta_{\mathrm{L}}=75^{\circ}$. (d) An overlapping geometry $\theta_{\mathrm{L}}=55^{\circ}$.

Axial valley formation along a plate boundary is a complex process dependent on spreading rate and interactions between brittle and ductile layers [26], however at the scale of the regions of interest for this study at the ends of the CIR segments, we are able to model the plate boundary as a Mode I extensional crack [23]. Mode I cracks are a good approximation of the segment tip behaviour within brittle crust and the rotation of stresses and the fault fabrics are closely analogous to those observed around crack tips in fracture mechanics studies of brittle materials [27]. Zero-displacement boundary conditions were set along the upper and lower edges of the model grid to avoid model distortion. The area of interest was set a significant distance from the grid boundaries to avoid boundary effects. The direction of the stress field at any 
grid point is given by the stress tensors with the maximum magnitude oriented at $90^{\circ}$ (normal to the crack) at the crack tip. The rotation of the stress tensor field rotates from the $90^{\circ}$ equilibrium orientation upon interaction with adjacent stress fields generated by crack tips, therefore modelling the conditions within an NTD. A range of model geometries were run and these demonstrate that the stress tensor (central stress tensor) located centrally between the crack tip is a reliable reference for the particular geometries or segment tip separations for small offset NTDs.

For crack tips with a large positive separation ratio (greater than shown in Fig. 1b), the central stress tensor will be orientated at or close to $90^{\circ}$, parallel to the farfield extension direction. As the segment tips get closer together the stress fields generated by the segments interact, and the central stress tensor rotates. The degree of rotation is controlled by the separation ratio (Fig. 1).

Fig. 2 shows the results of a series of numerical modelling experiments conducted to find the relationship between the separation ratio of two segments at an NTD and the nature of the orientation of the central stress tensor, measured using the previously defined angles $\theta_{\mathrm{L}}$ (for a left-stepping offset) or $\theta_{\mathrm{R}}$ (for a right-stepping offset). Positive separation ratios represent under-lapping segments, a ratio equal to 0 represents a simple stepping configuration and negative values represent over-lapping segments (Fig. 1). The $Y$-axis relates these separation ratios to corresponding central stress tensor rotations in the models. Fig. 2 shows that the orientation of the central stress tensor varies by $57^{\circ}$ over a limited separation ratio range of \pm 1.0 . The separation ratio range for the CIR NTDs, through measurement of the central tensor rotation, map to model separation ratios between +0.5 and +1.1 . That is, we use the observed fabric centrally between the segment tips to predict the central stress tensor orientation which is then used to determine the model separation ratios. They all fall in a critical zone of significant rotation predicted by the numerical models (Fig. 2).

The observed angles $150^{\circ}, 157^{\circ}$ and $154^{\circ}$ for NTDs C, $\mathrm{D}$ and $\mathrm{H}$ respectively are corrected to give the equivalent tensor angles of rotation of the fabrics on the orthogonal model grid. The resulting values of $92^{\circ}, 99^{\circ}$ and $96^{\circ}$ respectively, are plotted in Fig. 2. These values correspond to model separations falling within the region of the graph showing significant rotation of the central stress tensor. NTDs C and D have a similar magnitude of aspect ratio and therefore exhibit a similar obliquity of fabrics at their centre. NTD H has a greater aspect ratio and therefore has a higher degree of obliquity in the central basin. The model results show that the natural geometries of NTDs along the CIR and presumably along other ocean ridges have overlap geometries that correspond with those for which there is maximum variation in the predicted orientation of the central stress tensor. We therefore propose that the orientation of the central stress tensor is a sensitive indicator of the mechanical behaviour of NTD segment tips.

\section{Model application to the CIR}

The CIR is located in the Indian Ocean and forms the northerly component of the Rodrigues Triple Junction

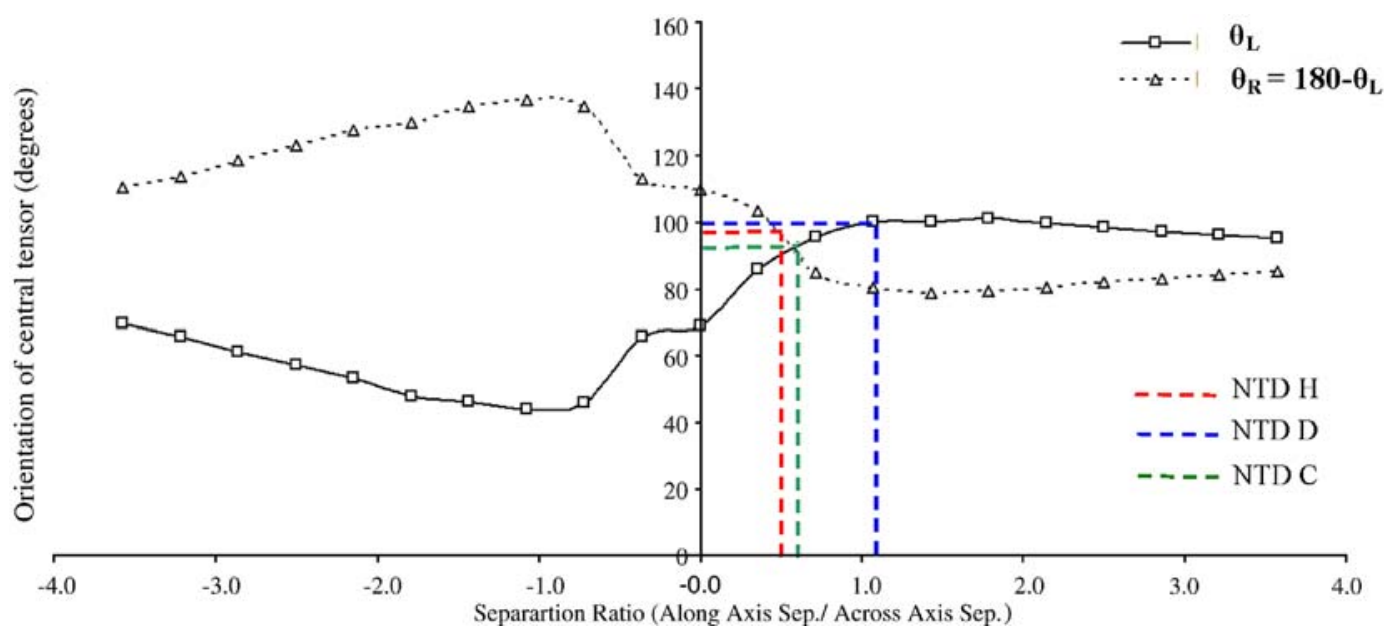

Fig. 2. Results from a continuum of along-axis separation experiments, where segment tip separation is measured as an along- and across-axis aspect ratio and is plotted against the central tensor rotation angle, $\theta_{\mathrm{L}}$ for left-stepping and $\theta_{\mathrm{R}}$ for right-stepping tip geometry. Significant rotation is observed throughout each experiment, with a rotational range of $57^{\circ}$. Construction lines for NTDs C, D and $\mathrm{H}$ are shown relating observed fabric rotations of $\theta_{\mathrm{R}}=92^{\circ}, \theta_{\mathrm{L}}=99^{\circ}$ and $\theta_{\mathrm{R}}=96^{\circ}$ respectively (after correction for placement from the oblique CIR axis on to the orthogonal model grid) to each separation ratio for each of the model tips for an equivalent rotation of the central model stress tensors. 
(Fig. 3). Approximately $700 \mathrm{~km}$ of swath bathymetry data and $560 \mathrm{~km}$ of sidescan data were collected along the CIR between 18 and $21^{\circ} \mathrm{S}$. The TOBI sidescan data were collected by the RRS Charles Darwin (Cruise CD127). The TOBI data has a resolution of $6 \times 6 \mathrm{~m}$ with a swath width of $6 \mathrm{~km}$. The multibeam data was collected by the $\mathrm{R} / \mathrm{V}$ Marion Dufresne during the Magofond Cruise in 1999 using a Thomson Marconi swath bathymetry system, which has a spatial resolution of $20 \mathrm{~m}$ at $3000 \mathrm{~m}$ water depth [28]. The swath width for the bathymetric data is $17 \mathrm{~km}$, generally six times the water depth.

The CIR spreads at a rate which varies along-axis between $54 \mathrm{~mm} \mathrm{a}^{-1}$ near the Rodrigues Triple Junction (RTJ) to approximately $30 \mathrm{~mm} \mathrm{a}^{-1}$ north of the equator [29]. This region of the Central Indian Ocean Ridge is spreading at approximately $45 \mathrm{~mm} \mathrm{a}^{-1}[28]$. Within the survey area there are eleven segments separated by three transform faults and eight NTDs. Segments within the study area range in length from 10 to $73 \mathrm{~km}$, and the along-axis separation of the segments at the NTDs is constrained within $2 \mathrm{~km}$. Table 1 summarises the discontinuity statistics within the study area, and the criteria for determining segment length are now briefly described. The line of measurement of segment length lies within the axial valley and between the tips, terminations or transform intersections for a particular segment. For larger segments, the segment length is measured between points along the segment trace coinciding with the initiation of change in the orientation of the fault fabrics into the bounding fracture zones. For NTDs, the segment tips are identified from bathymetry and sidescan data as the region proceeding either an abrupt change in the orientation of the valley

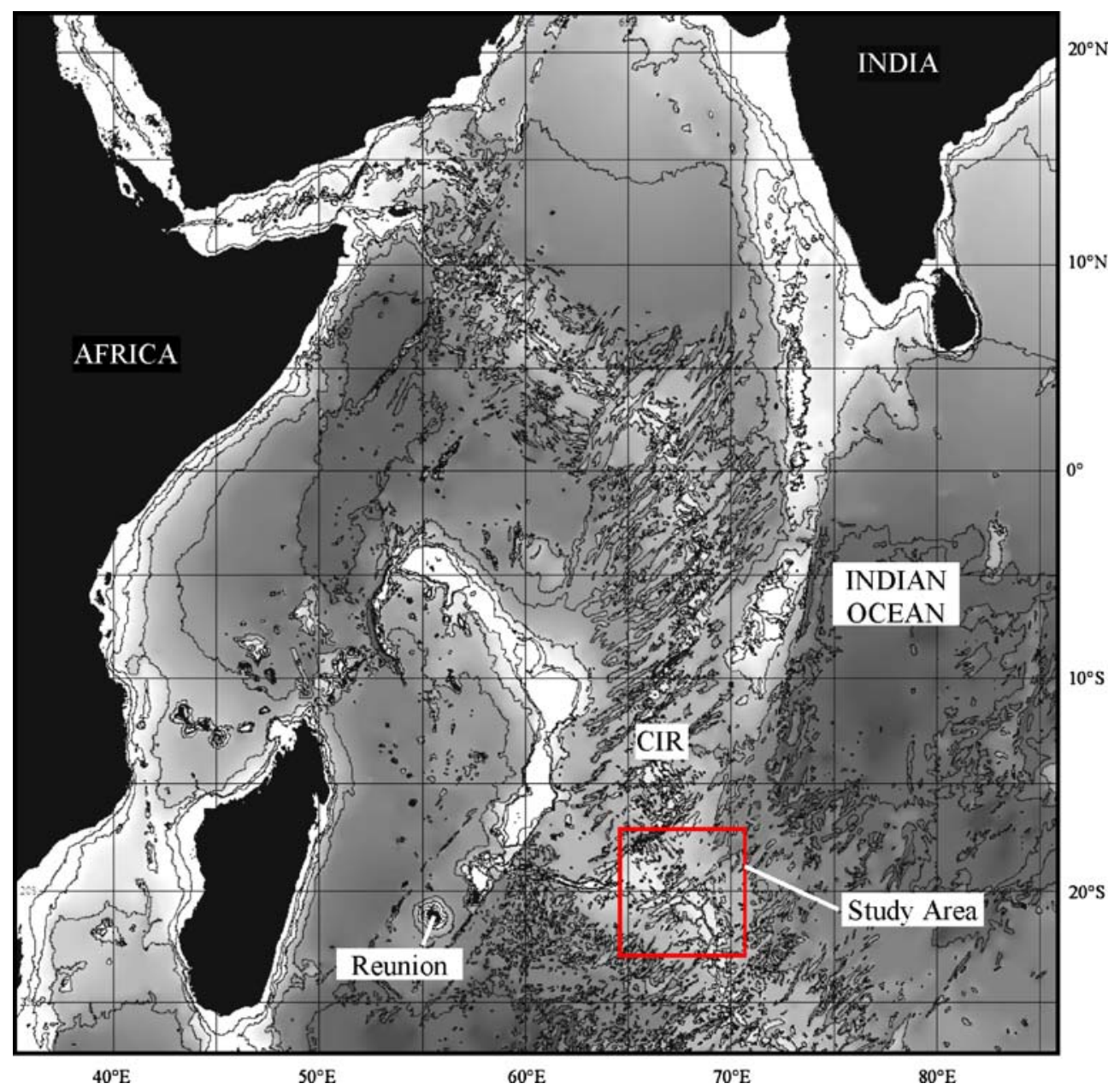

Fig. 3. Study area location map created from the GEBCO Digital Atlas [43]. The study area is located within the red box centred along the Central Indian Ridge (CIR). The bathymetry is contoured at a $500 \mathrm{~m}$ interval. 
Table 1

A summary of discontinuity statistics along the CIR

\begin{tabular}{|c|c|c|c|c|c|c|c|}
\hline \multirow[t]{2}{*}{ Name $^{a}$} & \multirow[t]{2}{*}{ Segments ${ }^{b}$} & \multirow[t]{2}{*}{ Sense } & \multirow{2}{*}{$\frac{\text { Along-axis offset }}{(\mathrm{km})}$} & \multirow{2}{*}{$\frac{\text { Across-axis offset }}{(\mathrm{km})}$} & \multirow[t]{2}{*}{ Interpreted type ${ }^{c}$} & \multirow[t]{2}{*}{ Azimuth $^{\mathrm{d}}$} & \multirow[t]{2}{*}{ Depth range } \\
\hline & & & & & & & \\
\hline NTD A & 9 and 10 & Right & 5 & 11.3 & Over-lapping with high & - & - \\
\hline NTD B & 10 and 11 & Left & 4 & 11.5 & Over-lapping with basin & - & - \\
\hline NTD C & 11 and 12 & Right & -0.5 & 4.9 & Under-lapping with basin & - & - \\
\hline NTD D & $15 \mathrm{a}$ and $15 \mathrm{~b}$ & Left & -0.9 & 3.8 & Under-lapping with basin & - & - \\
\hline NTD E & $15 \mathrm{~b}$ and $15 \mathrm{c}$ & Left & 2 & 4.8 & Over-lapping with high & - & - \\
\hline NTD F & $15 \mathrm{c}$ and $15 \mathrm{~d}$ & Right & 0 & 3.0 & Stepping with high & - & - \\
\hline NTD G & $15 \mathrm{~d}$ and $15 \mathrm{e}$ & Right & -1 & 1.6 & Under-lapping with basin & - & - \\
\hline NTD H & $15 \mathrm{e}$ and 16 & Right & -3.8 & 4.5 & Under-lapping with high & - & - \\
\hline Fracture Zone 1 & 12 and 13 & Left & - & 31.3 & Transform & 57 & $2840-3760$ \\
\hline Fracture Zone 2 & 13 and 14 & Left & - & 62.8 & Transform & 59 & $3320-4140$ \\
\hline Egeria Transform & 14 and $15 \mathrm{a}$ & Left & - & 45.7 & Transform & 59 & $2860-3920$ \\
\hline
\end{tabular}

a The NTDs are labelled A to H from south to north along the Central Indian Ridge, within the study area (Fig. 3).

b The nomenclature for the CIR segments is from [30].

${ }^{c}$ Based on interpreted over-lapping, under-lapping or stepping segment tip geometries. The description is based on observed centralised feature within the NTD.

${ }^{d}$ The azimuth is an average of the measurements recorded at intervals along the length of the PTDZ (Principal Transform Displacement Zone) using GIS software with an error of approximately $2^{\circ}$.

wall, or a point immediately preceding a zone of tectonised crust interpreted as a process zone at the end of a segment.

The across-axis offset for each NTD within the study area ranges between 2 and $10 \mathrm{~km}$. For each NTD the along axis separation of the segment tips is much less than the across axis separation. The initial interpretation of the segment terminations for each NTD, used to measure the offsets, have been identified using bathymetry and sidescan data. These observations include the curvature in the volcano-tectonic fabrics and valley walls, the presence of significant tectonism and fissuring of the lithosphere and an accumulation of volcanic construction, particularly hummocky volcanic terrains. The tip is interpreted where the valley floor and the volcanotectonic features are no longer visible, usually terminated by a steep scarp. Both left- and right-stepping senses of offset are observed for the NTDs along the CIR.

The dominant observable features which show rotation within an NTD include basins and tectonically controlled constructional ridges, also referred to as septal offsets [4]. The obliquity of these features along with measurements of the surrounding fault fabrics are used as a means of measuring stress rotations [31]. These central features are also a point of reference for co-location of the model central stress tensors showing an equivalent rotation (refer

Table 2

A summary of model fit statistics

\begin{tabular}{|c|c|c|c|c|c|c|c|c|c|}
\hline \multicolumn{6}{|c|}{ Interpreted parameters } & \multicolumn{4}{|c|}{ Model derived parameters } \\
\hline NTD & Segment & $\begin{array}{l}\text { Segment } \\
\text { length } \\
(\mathrm{km})^{\mathrm{a}}\end{array}$ & $\begin{array}{l}\text { Stepping } \\
\text { sense }\end{array}$ & $\begin{array}{l}\text { Feature } \\
\text { orientation } \\
\left(^{\circ}\right)\end{array}$ & $\begin{array}{l}\text { Interp. } \\
\text { offset } \\
\text { ratio }^{b}\end{array}$ & $\begin{array}{l}\text { Tensor } \\
\text { orientation } \\
\left({ }^{\circ}\right)^{c}\end{array}$ & $\begin{array}{l}\text { Model } \\
\text { offset ratio } d\end{array}$ & $\begin{array}{l}\text { Length of predicted } \\
\text { damage zone } \\
(\mathrm{km})\end{array}$ & $\begin{array}{l}\text { Damage zone as } \\
\% \text { of segment } \\
\text { length }(\%)\end{array}$ \\
\hline \multirow[t]{2}{*}{$\mathrm{C}$} & 11 & $59.8 \pm 1$ & Right & $150 \pm 2$ & $0.1 \pm 0.2$ & $60 \pm 2$ & 0.7 & $2.8 \pm 0.5$ & $4.7 \pm 0.8$ \\
\hline & 12 & $13.9 \pm 1$ & & & & & & $1.7 \pm 0.5$ & $12.2 \pm 3.7$ \\
\hline \multirow[t]{2}{*}{$\mathrm{D}$} & $15 \mathrm{a}$ & $57.4 \pm 1$ & Left & $157 \pm 2$ & $0.2 \pm 0.3$ & $67 \pm 2$ & 1.1 & $2.0 \pm 0.5$ & $3.5 \pm 0.9$ \\
\hline & $15 b$ & $53.0 \pm 1$ & & & & & & $2.5 \pm 0.5$ & $4.7 \pm 0.9$ \\
\hline \multirow[t]{2}{*}{$\mathrm{H}$} & $15 \mathrm{e}$ & $12.6 \pm 1$ & Right & $154 \pm 2$ & $0.8 \pm 0.3$ & $64 \pm 2$ & 0.6 & $0.7 \pm 0.5$ & $5.6 \pm 4.0$ \\
\hline & 16 & $73.3 \pm 1$ & & & & & & $0.2 \pm 0.5$ & $0.3 \pm 0.7$ \\
\hline
\end{tabular}

\footnotetext{
a The interpreted segment lengths based on observation of the volcano-tectonic fabrics and segment morphology.

b The interpreted NTD offset ratio from the CIR data measured as the separation ratio between the along axis $(Y)$ and across axis $(X)$ separations of the interpreted segment tips $(Y / X)$.

c The tensor orientations match the feature orientations observed at the CIR NTDs after correction for the orthogonal grid used in the models and the obliquity of the CIR axis to this grid.

${ }^{\mathrm{d}}$ The model offset ratio values are derived from the model segment tip positions generated by matching the corrected rotation of the stress tensor values with the feature rotations observed from the CIR NTDs.
} 
to Fig. 2). The construction lines for the CIR NTDs are shown on Fig. 2 linking rotation to model aspect ratio. We focus on NTDs C, D and $\mathrm{H}$ as a representative sample of the NTD offsets and geometries observed in the study area. NTDs C and D are similar in geometry but have different senses of offset and therefore explore the changes in the stress fields generated at NTDs attributable to segment offset direction. NTD H, as with NTD C, has a right-stepping sense but the offset geometry has a larger aspect ratio and therefore these models compare changes in stress field rotation relative to aspect ratio. The separation of the other NTDs is a combination of these parameters and are therefore measured but not included as part of the detailed analysis. The maximum magnitude of fabric rotation observed within NTDs C, D and H is within $7^{\circ}$. Fig. 2 allows the measurement of the orientations of the central morphological features and tectonic fabrics within the CIR NTDs, to be correlated with a specific modelled separation ratio, which has produced the same orientation of the central tensor within the numerical models. The range of separation ratios predicted for NTDs $\mathrm{C}, \mathrm{D}$ and $\mathrm{H}$ varies significantly from the interpreted range of separation ratio based on interpretation of tip locations from the morphology and tectonic fabrics along the CIR. The interpreted CIR NTD separation ratios, range from +0.1 to +0.8 (Table 2). We propose that the variation between these results indicates that the measurement of geometries directly from the CIR morphology is unlikely to be as informative as quantifying geometries by the observation of localised rotation in the ridge fabrics.

These results remove the need to rely on estimates of tip positions at the terminations of segments, but rather require careful observation of fabric rotation in the centre of the NTD to infer the NTD geometry from the model results. The results show that these two parameters, geometry and stress field rotation are strongly linked in the context of an NTD. This has important applications to understanding the fault sets and larger scale morphologies developing within an NTD.

\section{Model results}

\subsection{NTD $C-$ segments 11 and 12}

NTD C offsets segments 11 and 12 by a distance of $5.4 \mathrm{~km}$ orthogonal to the ridge axis and has a rightstepping sense of offset (Fig. 4). The interpreted segment tips under-lap by $0.5 \mathrm{~km}$, which gives a separation ratio of 0.1 (Table 2). The strike of the neovolcanic zone corresponds to a bathymetric deep for each segment (Fig. 4b). Analysis of the volcano-tectonic morphology of the inner valley floor shows that segment tips are dominated by fault fabrics and hummocky volcanic terrain. The central basin is a dominant feature within the NTD. It has a depth of $80 \mathrm{~m}$ and a long axis orientation of $150^{\circ}$. The surrounding faults accommodated within the discontinuity show significant curvature around this basin. The orientation of the basin, with consideration of the surrounding faults within the NTD, is used as a point of reference for model fitting across the NTD i.e. point of angular comparison with the central tensor in the numerical model. We use the longaxis orientation of the basin as a measure of the rotation of the stresses in the central region of the NTD.

The tensor angle deflection predicted by the numerical models is shown in Fig. $4 \mathrm{c}$ as colour coded zones. The tensor angle deflection is a measure of the rotation of the stress tensors predicted by the numerical model away from an equilibrium tensor orientation orthogonal to the ridge axis trend. The region between the segment tips produces a range of rotational deflection between $0^{\circ}$ and $12^{\circ}$. The central basin indicated in Fig. $4 \mathrm{a}$, corresponds to a zone of rotation between $0^{\circ}$ and $2^{\circ}$.

The model tip locations are shown on Fig. $4 \mathrm{~d}$, and the distances between the model derived segment tips and the tips interpreted from the bathymetry and sidescan data are shown by $\alpha 1$ and $\alpha 2$. The model tips are located behind the interpreted tip locations for both segments. The axial valley of segment 11 in which the model tip is located, narrows and extends ahead of the model tip locations. These regions of the data show much less well developed hummocky texture and are interpreted to be more tectonically controlled. We propose that these regions represent zones of focussed stress analogous to the regions of elevated stress associated with the tips of extensional or Mode I fractures.

\subsection{NTD D- segments $15 a$ and $15 b$}

NTD D offsets segments $15 \mathrm{a}$ and $15 \mathrm{~b}$ by a distance of $3.4 \mathrm{~km}$ orthogonal to the ridge axis and has a left-stepping sense of offset (Fig. 5). The interpreted segment tips under-lap by $0.9 \mathrm{~km}$, and have a separation ratio of 0.2 (Table 2). Segment 15 a has a particularly tectonised tip within the zone of segment termination Fig. 5a and b. The region of termination for segment $15 \mathrm{~b}$ shows much less tectonism and more volcanic construction, particularly ahead of the interpreted tip. The segment tip also narrows significantly as it approaches the NTD.

NTD D contains ridges and basins, which have clear obliquity to the fabrics found within the main segments. A heavily faulted basin oriented at $157^{\circ}$ and $60 \mathrm{~m}$ in depth dominates the central region of this NTD (Fig. 5a and b). 

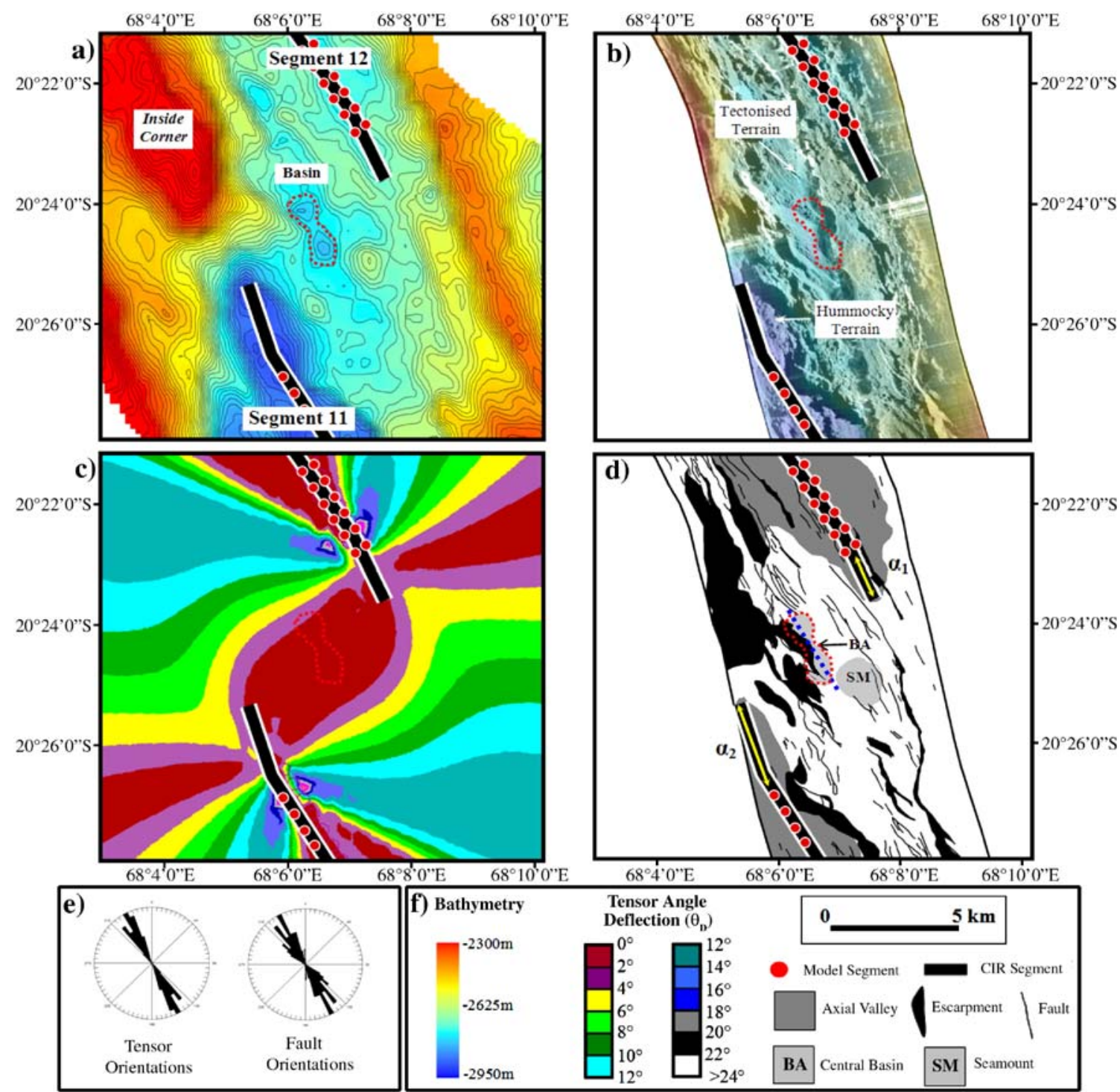

Fig. 4. Analysis for NTD C. The model segments are shown by the red circles and the interpreted segments by the black lines. (a) Bathymetric map of NTD C (20 m contour interval). (b) TOBI sidescan data colour shaded for depth using the bathymetry colour scale. (c) Contoured tensor angle deflection $\left(\theta_{\mathrm{D}}\right)$ from the plate motion vector $\left(58^{\circ}\right)$, contoured at $\pm 2^{\circ}$ intervals. $\theta_{\mathrm{R}}$ or $\theta_{\mathrm{L}}=58^{\circ} \pm \theta_{\mathrm{D}}$. The central basin is located at $68^{\circ} 06^{\prime} 29^{\prime \prime} \mathrm{E}$ and $20^{\circ} 24^{\prime} 20^{\prime \prime} \mathrm{S}$. (d) Interpretation based on sidescan and bathymetry data. The model segments are shown by the red circles and the axial valleys of the interpreted segments are shown in dark grey. The modelled segment tips are set back from the interpreted segment valley $\left(\alpha_{1}\right.$ and $\left.\alpha_{2}\right)$. The blue dashed line indicates the orientation of the Central Basin. (e) Rose diagrams of the stress tensor and fault fabric orientations which show a close correlation for the interior of the NTD. The tensor orientations have a mean of $149^{\circ}$, standard deviation of $20^{\circ}$ and a median value of $153^{\circ}$. The fault orientations have a mean of $143^{\circ}$, a standard deviation of $29^{\circ}$ and a median value of $147^{\circ}$. (f) Key for the bathymetry, tensor rotation and interpretation figures.

Well formed ridges $80-100 \mathrm{~m}$ in height link the inside corners of this NTD in a similar fashion to the outside corner linkage of the septal offsets described by $[32,4]$. The pattern of orientation and magnitude of the principal stress tensors differs significantly from those observed for NTD C (Fig. 5c). The zone between the segments' tips produces a range of rotational deflection between $0^{\circ}$ and $24^{\circ}$. The contours representing tensor rotations greater than $24^{\circ}$ (coloured white) are largely rotations attributable to individual segment tips rather than stress field interactions in the central region of the NTD.

Segment 15a has a high degree of tectonism and hummocky terrain associated with the tip region. In contrast segment $15 \mathrm{~b}$ has little tectonism and a much smoother acoustic texture indicated by smaller hummocky mounds and smoother volcanic flows. These 
differences could relate to different processes occurring at each segment tip. Tip propagation is likely to be associated with significant tectonism and the presence of a well developed damage zone. Segment tip retreat is likely to relate to the subdued morphology and a less tectonism in this damage zone. One interpretation of these observations is that one of the segments is in retreat; the other segment is propagating, which would result in the migration of this NTD northwards.

\subsection{NTD $H-$ segments $15 e$ and 16}

NTD H offsets segments $15 \mathrm{e}$ and 16 by a distance of $4.1 \mathrm{~km}$ orthogonal to the ridge axis and has a right-
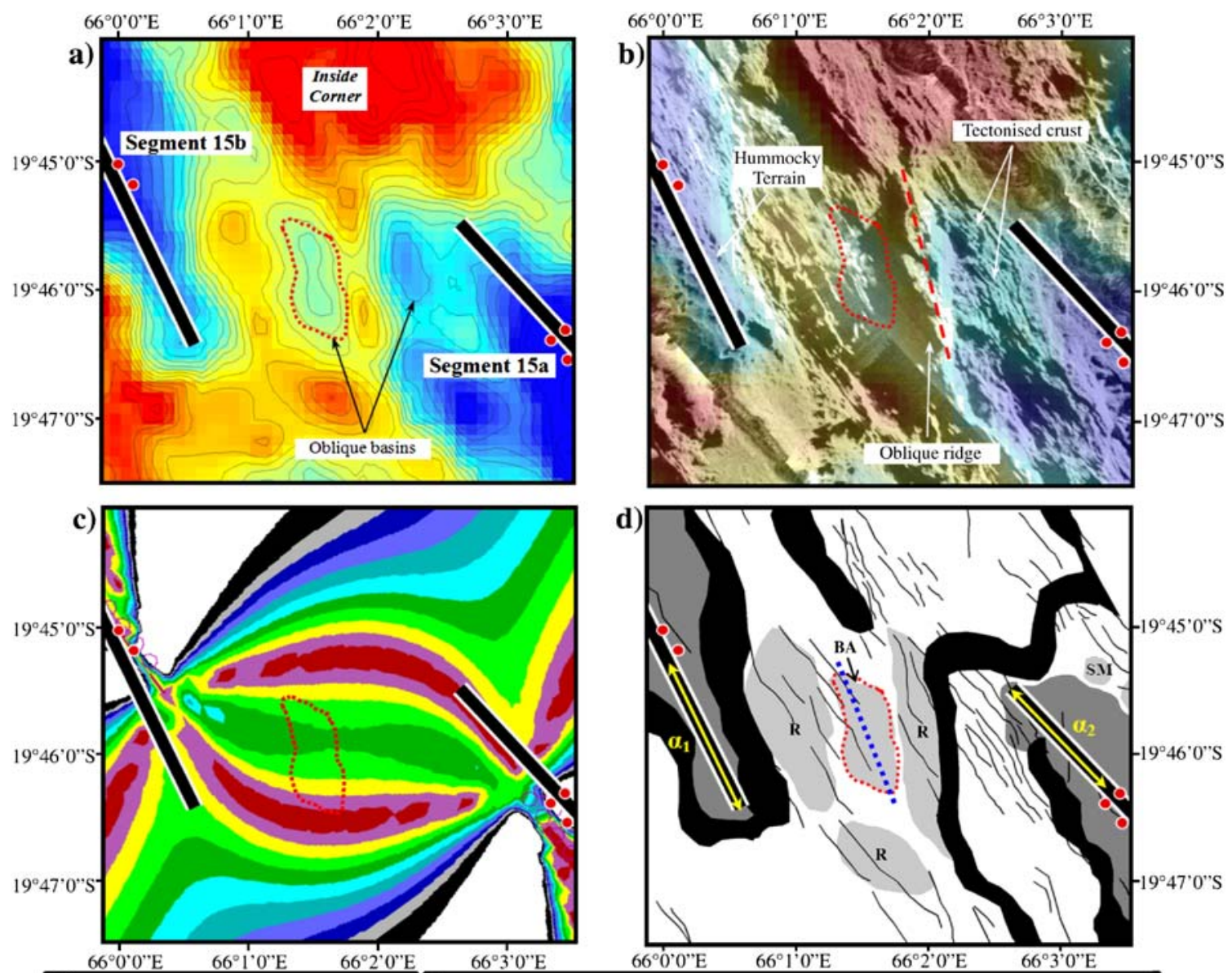

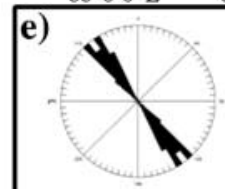

Tensor

Orientations

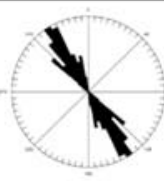

Fault

Orientations
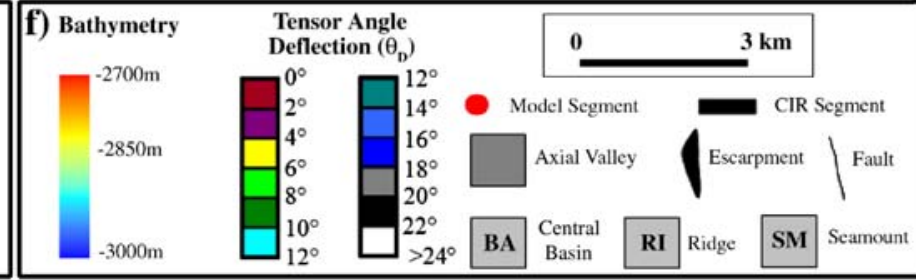

Fig. 5. Analysis for NTD D. The model segments are shown by the red circles and the interpreted segments by the black lines. (a) Bathymetric map of NTD D (20 m contour interval). (b) TOBI sidescan data colour shaded for depth using the bathymetry colour scale. (c) Contoured tensor angle deflection $\left(\theta_{\mathrm{D}}\right)$ from the plate motion vector $\left(58^{\circ}\right)$, contoured at $\pm 2^{\circ}$ intervals. $\theta_{\mathrm{R}}$ or $\theta_{\mathrm{L}}=58^{\circ} \pm \theta_{\mathrm{D}}$. The central basin is located at $66^{\circ} 1^{\prime} 30^{\prime \prime} \mathrm{E}$ and $19^{\circ} 45^{\prime} 45^{\prime \prime} \mathrm{S}$. (d) Interpretation is based on sidescan and bathymetry data. The model segments are shown by the red circles and the axial valleys of the interpreted segments are shown in dark grey. The modelled segment tips are set back from the interpreted segment valley $\left(\alpha_{1}\right.$ and $\left.\alpha_{2}\right)$ and chaotic zones are observed at the terminations of segments suggesting brittle or inelastic deformation of the lithosphere. The blue dashed line indicates the orientation of the Central Basin. (e) Rose diagrams of the stress tensor and fault fabric orientations which show a close correlation for the interior of the NTD. The tensor orientations have a mean of $141^{\circ}$, standard deviation of $19^{\circ}$ and a median value of $144^{\circ}$. The fault orientations have a mean of $147^{\circ}$, a standard deviation of $18^{\circ}$ and a median value of $149^{\circ}$. (f) Key for the bathymetry, tensor rotation and interpretation figures. 
stepping sense of offset (Fig. 6). The interpreted segment tips under-lap by $3.4 \mathrm{~km}$, which gives a separation ratio of 0.8 (Table 2). It has a very similar geometry and stress distribution to NTD C. However, the prediction of segment tip distribution from the numerical model shows a much closer correlation to the interpreted position of the segment 16 tip. This is significant because morphological observations and volcano-tectonic fabric analysis suggest that this segment is a more magmatically robust segment than the others located within the study area. We explain the apparent lack of large-scale fracturing at the segment tips as being due to a more diffuse and small-scale fault population due to a weaker lithosphere being unable to accommodate significant faulting. We surmise that increased magma supply to the segment tip can suppress these larger-scale fault fabrics.

\subsection{Segment and model tip positions}

The results show the model aspect ratios and positioning based on the orientation of features, particularly central basins or highs within small-offset NTDS, are predominantly influenced by the perturbations in the stresses generated by the interaction of the respective segment tips. In order to compare the numerical model data with the CIR NTD geometries, the long-axis orientation of the basin or topographic high at the centre of the NTD is used to correlate with the obliquity of the stresses in the central region of the modelled NTD separations. Only the across-axis segment separation is used to scale the models based on the orientation of the neovolcanic zones. This independence enables the model to predict new segment tip locations based on the observed stress field orientations in the interior of the NTD.

The model tip locations are indicated on Figs. $4 d, 5 d$ and $6 \mathrm{~d}$ and are located behind the tip locations interpreted from morphology as shown by $\alpha 1$ and $\alpha 2$. Morphological change such as the narrowing and deepening of the axial valley is generally observed in these regions. The results suggest that the difference between the interpreted and model tip positions may be the result of a zone of focused stresses producing a damage zone ahead of the segment tips.

\section{The damage zone}

The results have demonstrated the influence of NTD geometry on the stress fields generated within a discontinuity. The greatest rotation of the central stress tensor occurred between separation ratios of +1 and -1 . Significantly, the separation ratios measured for the discontinuities along the CIR fall within this zone of significant change (Table 2).

Careful comparison of the observed segment ends along the CIR, along with the model results, suggest an underlying controlling mechanical process not identifiable solely from the survey data. Table 2 shows, that there is a consistent difference between the model tip positions and the interpreted positions. The model tip locations are set back from the interpreted segment ends by a distance up to $2.8 \mathrm{~km}$ and up to $12 \%$ of the length of a segment. The regions ahead of the predicted model tips show, in some segments a higher fault density, increased volcanism (mostly comprising hummocky mounds) and an elongated and narrower axial valley. Stresses for mode I cracks which are analogous to the segments modelled along the CIR are concentrated at the tips [23]. Observation of the tip regions for mode I cracks in studies related to fracture mechanics, have described the presence of a process zone ahead of the crack tip $[23,33,34]$. A process zone can be described as a region of softening ahead of a crack, produced by stresses at the crack tip promoting the development of finer-scale fissuring adjacent to the tip, weakening the material and promoting linkage of these fissures and eventually crack propagation. Our models and observations suggest that a broadly analogous zone of faulting, which we call a damage zone, is present ahead of some of the segment tips. The damage zone may act as a zone of crustal softening behaving inelastically with small scale fractures ahead of the true segment tip, produced by increased stresses in this region.

Defining the location of these sites therefore requires a clear distinction for the spatial definition of a mechanical segment, a damage zone and an NTD. The results suggest that there is a distinction between:

1. A mechanically open segment responding to far-field tensile stresses and showing brittle and elastic behaviour under extension through seafloor spreading

2. A damage zone showing distributed brittle and inelastic deformation

3. The physical discontinuity along the ridge axis experiencing rotation of the local stress fields and showing obliquity in the observable volcano-tectonic fabrics.

The segments in this study, interpreted from the bathymetry and sidescan sonar data, can therefore be redefined within a mechanical framework as a combination of a mechanically open segment defined by a linear region with the properties of a mode I fracture in an elastic sheet and an inelastic damage zone. 


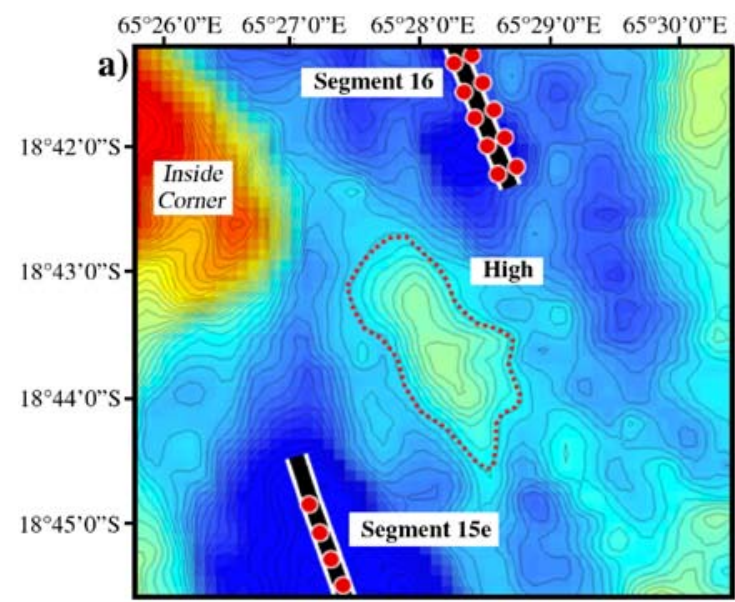

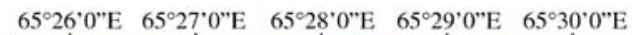
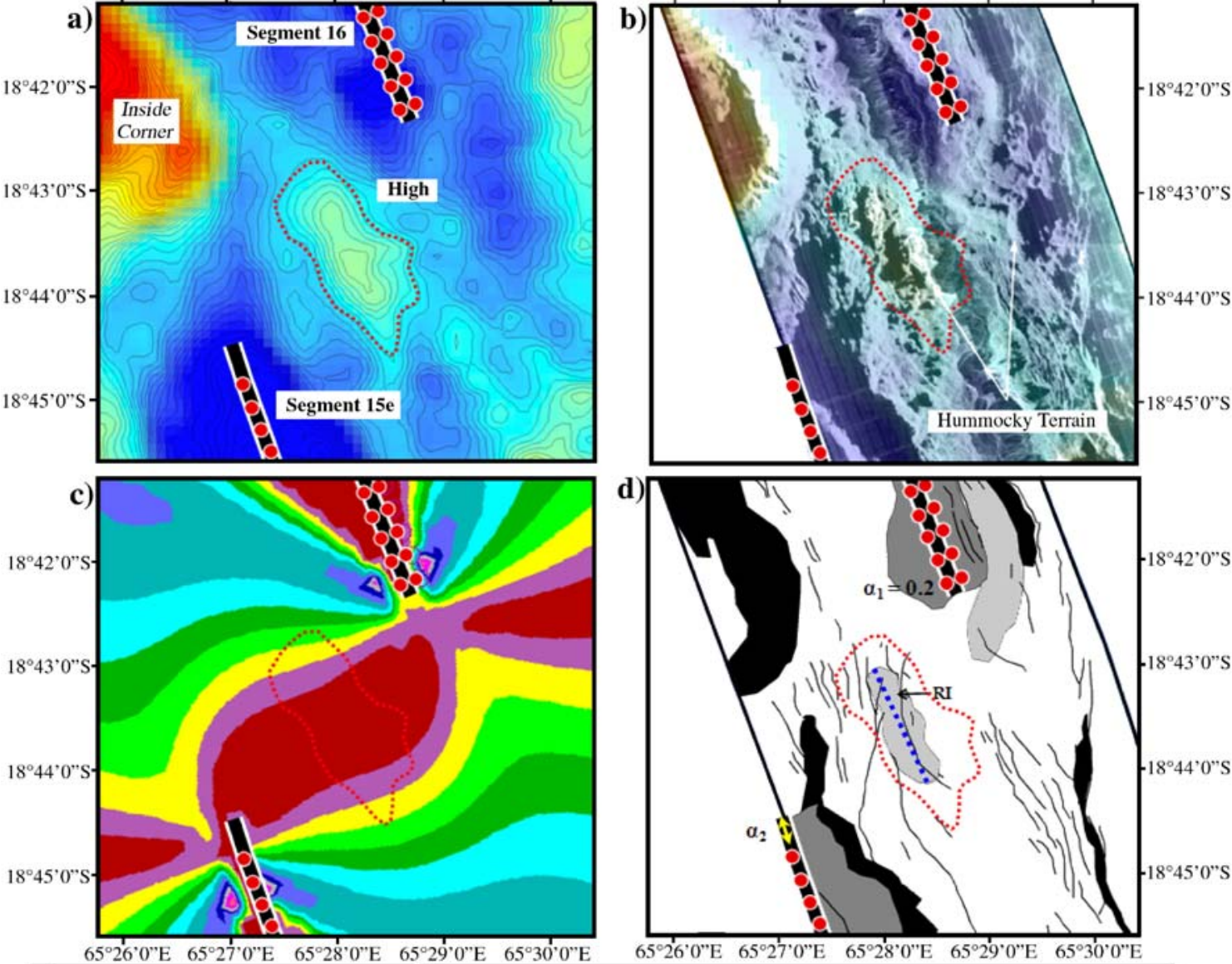

d)

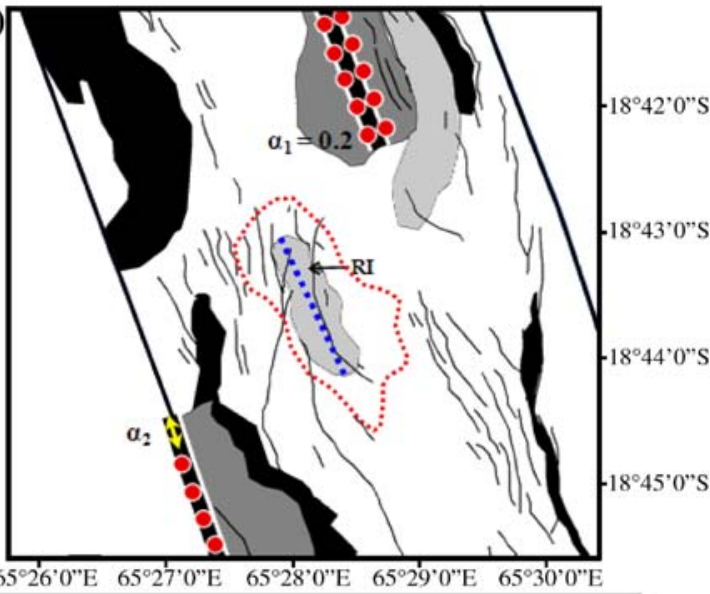

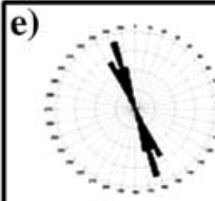

Tensor

Orientations

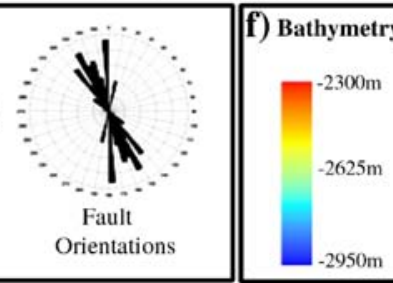

Tensor Angle
Deflection $\left(\theta_{\mathrm{p}}\right)$
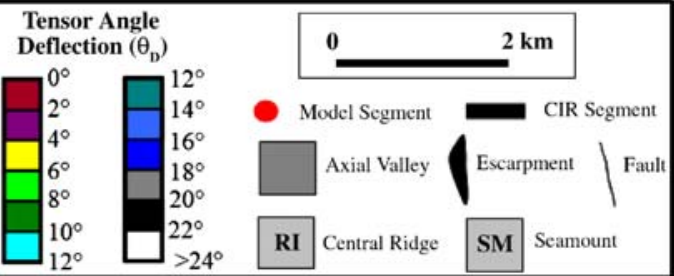

Fig. 6. Analysis for NTD H. The model segments are shown by the red circles and the interpreted segments by the black lines. (a) Bathymetric map of NTD H (contour interval $20 \mathrm{~m}$ ). (b) TOBI sidescan data colour shaded for depth using the bathymetry colour scale. (c) Contoured tensor angle deflection $\left(\theta_{\mathrm{D}}\right)$ from the plate motion vector $\left(58^{\circ}\right)$, contoured at $\pm 2^{\circ}$ intervals. $\theta_{\mathrm{R}}$ or $\theta_{\mathrm{L}}=58^{\circ} \pm \theta_{\mathrm{D}}$. The central high is located at $65^{\circ} 28^{\prime} 10^{\prime \prime} \mathrm{E}$ and $18^{\circ} 43^{\prime} 35^{\prime \prime} \mathrm{S}$. (d) Interpretation based on sidescan and bathymetry data. The axial valleys of the interpreted segments are shown in dark grey. The modelled segment tips are set back from the interpreted segment valley $\left(\alpha_{1}\right.$ and $\left.\alpha_{2}\right)$. (e) Rose diagrams of the stress tensor and fault fabric orientations which show a close correlation for the interior of the NTD. The tensor orientations have a mean of $143^{\circ}$, standard deviation of $44^{\circ}$ and a median value of $161^{\circ}$. The fault orientations have a mean of $155^{\circ}$, a standard deviation of $23^{\circ}$ and a median value of $157^{\circ}$. The fault orientations show a bimodal distribution. (f) Key for the bathymetry, tensor rotation and interpretation figures.

\subsection{Implications for hydrothermal activity within the damage zone}

The implications of this study point to a complex assemblage of structures both tectonic and volcanic directly influenced by NTD geometry and segment scale processes associated with discontinuities in ridge structure. It appears that the nature of the fault fabric orientations and hence the degree to which the permeability of the crust is increased may depend on how an NTD develops over time, reflecting the proximity of the tips and the nature of the geometry of a discontinuity. Given the criteria for the promotion of hydrothermal circulation, a damage zone has the potential to provide a suitable environment for hydrothermal circulation to initiate. In the context of our study, favourable locations 
for hydrothermal vent sites are likely to be found between the mechanical segment tip (predicted by the model) and the termination of the damage zone adjacent to the discontinuity along the ridge axis. Hydrothermal circulation in these regions is likely to be initiated where tectonic fabrics under geometrically influenced stress fields have persisted and are coupled with a suitable local heat source. There are discoveries and observations along other ocean ridges which correlate with these observations. On the slow spreading Mid Atlantic Ridge mechanisms for the formation of long-lived, tectonically hosted hydrothermal vent fields such as TAG $[15,35,36]$ and especially Rainbow [37,38] are poorly understood. The Rainbow hydrothermal vent field is a fault controlled hydrothermal system, associated with a non-transform discontinuity hosting ten discrete clusters of active black smoker $\left(\leq 364{ }^{\circ} \mathrm{C}\right)$ chimneys [39]. German and Lin [40] argue that both hydrothermal cooling which extends into the lower crust and heat release from serpentinisation could contribute to the required heat budget at sites like Rainbow. Cannat et al. [41] comment that the ends of many slow-spreading ridge segments exhibit a seafloor morphology that is different from that of the volcanically dominated segment centres, and serpentinised peridotites are often found to outcrop. Alternatively evidence has been found for along-axis magma penetration from the central part of a rift segment to the tip, resulting in a lateral shift of hydrothermal activity with time [e.g. [42]].

\section{Conclusions}

On the basis of the numerical modelling and spatial analysis of NTD geometry and structure along the CIR, we propose the following conclusions:

(1) We have shown that the complex nature of the segment tips with their associated tectonism and volcanism restricts the degree of interpretation from survey data. Identifying the segment tips from survey data in order to define the geometry and explain the fabrics within the NTD is particularly difficult.

(2) Numerical modelling has provided a new method of aiding in the interpretation of NTD geometry, understanding the stress fields generated by these geometries and understanding the response of the intra-NTD volcano-tectonic fabrics at a range of scales to the localised rotational effects generated at NTDs.

(3) NTD geometry and particularly the separation ratio is a critical factor in the rotational magnitude of the intra-NTD stress field and the obliquity of the fabrics observed. Large-scale features are particularly responsive to the rotations in the NTD stress field.

(4) The model data when mapped onto the CIR, suggests that there is a distinction between a mechanically open segment responding to farfield tensile stresses, a damage zone undergoing crustal softening and the physical discontinuity along the ridge axis. Interpretation from survey data encompasses the mechanical combination of these components.

(5) We have shown that the various factors influencing the rotation of fabrics within the NTD and complex fault development adjacent to the mechanically open segment tip and within the damage zone, promote the development of complex fault fabrics. The implications of an increase in permeability through complex fault structures lead to an enhanced potential for the promotion of hydrothermal circulation.

\section{Acknowledgements}

The Master, officers and crew of the R.V. Charles Darwin Cruise CD127 are thanked for their assistance. We are grateful to Daniel Sauter and Jérôme Dyment for providing access to the multibeam bathymetry data for our study area. We thank Debbie Smith for a careful review.

\section{References}

[1] K.C. Macdonald, P.J. Fox, L.J. Perram, M.F. Eisen, R.M. Haymon, S.P. Miller, S.M. Carbotte, M.-H. Cormier, A.N. Shor, A new view of the mid-ocean ridge from the behaviour of ridgeaxis discontinuities, Nature 335 (1988) 217-225.

[2] N.R. Grindlay, P.J. Fox, K.C. Macdonald, Second-order ridge axis discontinuities in the South Atlantic: morphology, structure, and evolution, Mar. Geophys. Res. 13 (1991) 21-49.

[3] N.R. Grindlay, P.J. Fox, Lithospheric stresses associated with non-transform offsets of the Mid-Atlantic Ridge: implications from a finite element analysis, Tectonics 12 (1993) 982-1003.

[4] S. Spencer, D.K. Smith, J.R. Cann, J. Lin, E. McAllister, Structure and stability of non-transform discontinuities on the Mid-Atlantic Ridge between $24^{\circ} \mathrm{N}$ and $30^{\circ} \mathrm{N}$, Mar. Geophys. Res. 19 (1997) 339-362.

[5] C.R. German, L.M. Parson, Distributions of hydrothermal activity along the Mid-Atlantic Ridge: interplay of magmatic and tectonic controls, Earth Planet. Sci. Lett. 160 (1998) 327-341.

[6] B. Murton, P. Blondel, G. Tuckwell, On the nature and implications of non-transform discontinuities along medium spreading ridges, BRIDGE Newsl. 12 (1997) 56-57.

[7] E. Gràcia, J.L. Charlou, J. Radford-Knoery, L.M. Parson, Nontransform offsets along the Mid-Atlantic Ridge south of the Azores $\left(38^{\circ} \mathrm{N}-34^{\circ} \mathrm{N}\right)$ : ultramafic exposures and hosting of hydrothermal vents, Earth Planet. Sci. Lett. 177 (2000) 89-103. 
[8] C.R.B. Lister, On the penetration of water into hot rock, J. R. Astron. Soc. 39 (1974) 465-509.

[9] M.C. Kleinrock, S.E. Humphris, Structural control on sea-floor hydrothermal activity at the TAG active mound, Nature 382 (1996) 149-153.

[10] S.E. Humphris, M.C. Kleinrock, Detailed morphology of the TAG active hydrothermal mound: insights into its formation and growth, Geophys. Res. Lett. 23 (1996) 3443-3446.

[11] E. Gràcia, D. Bideau, R. Hekinian, Y. Lagabrielle, L.M. Parson, Along-axis magmatic oscillations and exposure of ultramafic rocks in a second-order segment of the Mid-Atlantic Ridge $\left(33^{\circ} 43^{\prime} \mathrm{N}\right.$ to $\left.34^{\circ} 07^{\prime} \mathrm{N}\right)$, Geology 25 (1997) $1059-1062$.

[12] E. Gràcia, L.M. Parson, D. Bideau, Y. Lagabrielle, Second-order discontinuities in the Mid-Atlantic Ridge (34-38 N): ultramafic exposures in NTDs, Abstract of Paper to be Presented at AGU Fall Meeting, 1997, San Francisco, California, Eos, vol. 78, 1997, p. F692.

[13] C.R. German, L.M. Parson, H. Bougault, D. Coller, M. Critchley, A. Dapoigny, C. Day, D. Eardley, Hydrothermal exploration near the Azores Triple Junction: tectonic control of venting at slowspreading ridges? Earth Planet. Sci. Lett. 138 (1996) 93-104.

[14] C.R. German, E.T. Baker, C. Mevel, K. Tamaki, and the FUJI Science Team, Hydrothermal activity along the southwest Indian ridge, Nature 395 (1998) 490-493.

[15] M.A. Tivey, H. Schouten, M.C. Kleinrock, A near-bottom magnetic survey of the Mid-Atlantic Ridge axis at $26 \mathrm{~N}$ : implications for the tectonic evolution of the TAG segment, J. Geophys. Res. 108 (2003).

[16] L.M. Parson, C.L. Walker, D.R. Dixon, Hydrothermal vents and processes, in: L.M. Parson, C.L. Walker, D.R. Dixon (Eds.), Hydrothermal Vents and Processes, Geological Society Special Publication, vol. 87, 1995, pp. 1-2.

[17] C.R. German, E.T. Baker, G. Klinkhammer, Regional Setting for hydrothermal activity, in: L.M. Parson, C.L. Walker, D.R. Dixon (Eds.), Hydrothermal Vents and Processes, Geological Society Special Publication, vol. 87, 1995, pp. 3-15.

[18] K. Macdonald, D.S. Scheirer, S.M. Carbotte, Mid-ocean ridges: discontinuities, segments and giant cracks, Science 253 (1991) 986-994.

[19] M.D. Behn, J. Lin, M.T. Zuber, A continuum mechanics model for normal faulting using a strain-rate softening rheology: implications for thermal and rheological controls on continental and oceanic rifting, Earth Planet. Sci. Lett. 202 (2002) 725-740.

[20] T. Engelder, Stress Regimes in the Lithosphere, Princeton University Press, 1993.

[21] J.C. Jaeger, N.G.W. Cook, Fundamentals of Rock Mechanics, 3rd edition, 1979.

[22] ITASCA, Consulting Group Inc., Fast Lagrangian Analysis of Continuua, Version 3.4, Itasca Consulting Group, Inc., Minneapolis, Minn., 1999

[23] B.K. Atkinson, Fracture Mechanics of Rock, Academic Press, 1987.

[24] A.H. Lachenbruch, A simple mechanical model for oceanic spreading centres, J. Geophys. Res. 78 (1973) 3395-3417.

[25] D.J. Wright, Formation and development of fissures at the East Pacific Rise: implications for faulting and magmatism at midocean ridges, in: W.R. Buck, P.T. Delaney, Jeffrey A. Karson, Lagabrielle (Eds.), Faulting and Magmatism at Ocean Ridges, vol. 106, 1998, pp. 137-151

[26] Y. Chen, W.J. Morgan, Rift valley/no rift valley transition at midocean ridges, J. Geophys. Res. 95 (1990) 17,571-17,581.

[27] G.W. Tuckwell, Models of Structural Processes at Oceanic Plate Boundaries, PhD Thesis, University of Southampton, 1997.
[28] J. Dyment, Y. Gallet, A. Briais, R. Drolia, S. Gac, P. Gente, M. Maia, S. Mercuriev, P. Patriat, G. Pouliquen, T. Sasaki, K. Tamaki, C. Tamura, R. Thibaud, The Mongofond 2 cruise: a surface and deep-tow survey on the past and present Central Indian Ridge, InterRidge News, vol. 8, 1999, pp. 25-31.

[29] J.-C. Sempèrè, E.M. Klein, New insights in crustal accretion expected from Indian Ocean spreading centres, Eos 76 (1995) $113-120$.

[30] A. Briais, Structural analysis of the segmentation of the Central Indian Ridge between $20^{\circ} 30^{\prime} \mathrm{S}$ and $25^{\circ} 30^{\prime} \mathrm{S}$ (Rodriguez Triple Junction), Mar. Geophys. Res. 17 (1995) 431-467.

[31] G.W. Tuckwell, J.M. Bull, D.J. Sanderson, Numerical models of faulting at oblique spreading centres, J. Geophys. Res. 103 (1998) 15,473-415,482.

[32] J.-C. Sempèrè, J. Lin, H.S. Brown, H. Schouten, G.M. Purdy, Segmentation and morphotectonic variations along a slowspreading centre: the Mid-Atlantic Ridge $\left(24^{\circ} 00^{\prime} \mathrm{N}-30^{\circ} 40^{\prime} \mathrm{N}\right)$, Mar. Geophys. Res. 15 (1993) 153-200.

[33] P.A. Cowie, C.H. Scholz, Physical explanation for the displacement-length relationship of faults using a post-yield fracture mechanics model, J. Struct. Geol. 14 (1992) 1133-1148.

[34] P.A. Cowie, C.H. Scholz, On the formation of growth faults: an experimental study, J. Geophys. Res. 93 (1988) 3307-3320.

[35] R.B. Scott, P.A. Rona, B.A. McGregor, M.R. Scott, The TAG hydrothermal field, Nature 251 (1974) 301-302.

[36] P.A. Rona, G. Thompson, M.J. Mottl, J.A. Karson, W.J. Jenkins, D. Graham, M. Mallette, K. Von Damm, J.M. Edmond, Hydrothermal activity at the TAG hydrothermal field, Mid-Atlantic ridge crest at 26 N, J. Geophys. Res. 89 (1984) 11365-11378.

[37] Y. Fouquet, J.L. Charlou, H. Ondreas, J. Radford-Knoery, J.P. Donval, E. Douville, R. Apprioual, P. Cambon, H. Pellé, J.Y. Landuré, Discovery and first submersible investigations on the Rainbow hydrothermal field on the MAR $\left(3614^{\prime} \mathrm{N}\right)$, Eos, Trans. Am. Geophys. Union 78 (1997) 832.

[38] L.M. Parson, Non-transform offsets along the Mid-Atlantic Ridge south of the Azores $\left(38^{\circ} \mathrm{N}-34^{\circ} \mathrm{N}\right)$ : ultramafic exposures and hosting of hydrothermal vents, Earth Planet. Sci. Lett. 177 (2000) 103.

[39] C.R. German, G.P. Klinkhammer, M.D. Rudnick, The Rainbow hydrothermal plume, $3615^{\prime} \mathrm{N}$, MAR, Geophys. Res. Lett. 23 (1996) 2979-2982.

[40] C.R. German, J. Lin, The thermal structure of the oceanic crust, ridge spreading and hydrothermal circulation: how well do we understand their inter-connections? in: C.R. German, J. Lin, L.M. Parson (Eds.), Mid Ocean Ridges: Hydrothermal Interactions Between the Lithosphere and Oceans, Geophysical Monograph Series, vol. 148, 2004, pp. 1-18.

[41] M. Cannat, J. Cann, J. Maclennen, Some hard rock constraints on the supply of heat to mid-ocean ridges, from Mid Ocean Ridges: hydrothermal interactions between the lithosphere and oceans, Geophys. Monogr. 148 (2004) 111-149.

[42] S.G. Krasnov, I.M. Poroshina, G.A. Cherkashev, Geological setting of high-temperature hydrothermal activity and massive formation on fast- and slow-spreading ridges, in: L.M. Parson, C.L. Walker, D.R. Dixon (Eds.), Hydrothermal Vents and Processes, Geological Society Special Publication, vol. 87, 1995, pp. 17-32.

[43] IOC, IHO, BODC, Centenary Edition of the GEBCO Digital Atlas, published on CD-ROM on behalf of the Intergovernmental Oceanographic Commission and the International Hydrographic Organization as part of the General Bathymetric Chart of the Oceans; British Oceanographic Data Centre, Liverpool (2003). 